\title{
Effects of propofol and inhalational anesthetics on the optic nerve sheath diameter in patients undergoing surgery in the steep Trendelenburg position: a systematic review and meta-analysis
}

\author{
Jinkun Yang, Xueping Yang, Xijuan Li, Shan Ou \\ Department of Anesthesiology, Chengdu First People's Hospital, Chengdu, China \\ Contributions: (I) Conception and design: J Yang; (II) Administrative support: S Ou; (III) Provision of study materials or patients: J Yang; (IV) \\ Collection and assembly of data: J Yang, X Yang; (V) Data analysis and interpretation: J Yang, X Li; (VI) Manuscript writing: All authors; (VII) Final \\ approval of manuscript: All authors. \\ Correspondence to: Shan Ou. Department of Anesthesiology, Chengdu First People's Hospital, 18 Wanxiang North Road, Chengdu, China. \\ Email: composer163@163.com.
}

Backgroundz Optic nerve sheath diameter (ONSD) is recognized as a surrogate indicator of intracranial
pressure (ICP) during surgery. Due to the requirements of surgery, the adjustment to the steep
Trendelenburg position and the establishment of $\mathrm{CO}_{2}$ pneumoperitoneum can lead to an increase in ICP,
resulting in an increase in the ONSD. Anesthetic agents have different impacts on cerebral blood volume
and ICP. The aim of this study was to evaluate the effects of propofol and inhalational anesthetics on the
ONSD based on data from randomized controlled trials (RCTs). Methods: The electronic databases of PubMed, EMBASE, Ovid MEDLINE, the Cochrane Library, and other databases were searched systematically using specified keywords from their inception to June 2021. The Chi-square test and $\mathrm{I}^{2}$ test were used to evaluate the heterogeneity across the studies. The weighted mean difference (WMD) with $95 \%$ confidence interval (CI) were adopted to analyze continuous data.

Results: A total of 379 patients from 7 studies were involved in this meta-analysis. There were borderline significant differences in the ONSD atT2 between propofol and the control group: T2 (WMD =-0.15, 95\% CI: $-0.31,-0.00, \mathrm{P}=0.005$ ). There were significant differences at T3 (WMD $=-0.23,95 \% \mathrm{CI}:-0.42,-0.05$, $\mathrm{P}=0.013$ ) and $\mathrm{T} 4$ (WMD $=-0.18,95 \% \mathrm{CI}:-0.29,-0.07, \mathrm{P}=0.001)$. After statistical verification, there was no significant difference in the ONSD at T1 between the 2 groups: T1 (WMD $=-0.08,95 \%$ CI: $-0.26,0.10$, $\mathrm{P}=0.368)$. There were also no significant differences in mean arterial pressure (MAP) $(\mathrm{P}=0.654,0.445,0.698$, and 0.562 , respectively) and end tidal $\mathrm{CO}_{2}\left(\mathrm{ETCO}_{2}\right)(\mathrm{P}=0.081,0.506,0.126$, and 0.983 , respectively) at T1, $\mathrm{T} 2, \mathrm{~T} 3$ and $\mathrm{T} 4$ between propofol and inhalational anesthetics.

Discussion: The findings in the present study indicated that the ONSD during propofol anesthesia was significantly lower than that during inhalational anesthesia after adopting the Trendelenburg position and $\mathrm{CO}_{2}$ pneumoperitoneum. These analysis results suggest that propofol anesthesia may help to minimize changes in ICP compared to inhalational anesthetics.

Keywords: Propofol; inhalational anesthetics; optic nerve sheath diameter (ONSD); Trendelenburg position; $\mathrm{CO}_{2}$ pneumoperitoneum

Submitted Jul 27, 2021. Accepted for publication Sep 16, 2021.

doi: 10.21037/apm-21-2363

View this article at: https://dx.doi.org/10.21037/apm-21-2363 


\section{Introduction}

During robot-assisted laparoscopic radical prostatectomy (RLRP) and laparoscopic gynecological surgery, it is necessary to adjust to a steep Trendelenburg position and establish a $\mathrm{CO}_{2}$ pneumoperitoneum to facilitate the exposure of the surgical area, but this may cause the intracranial pressure (ICP) to be $10 \mathrm{mmHg}$ higher than the baseline $(1,2)$. The increase in ICP leads to a decrease in cerebral perfusion pressure, which is related to postoperative neurological complications, including cerebral ischemia and cerebrovascular diseases (3).

Anesthetic agents can have an impact on ICP during surgery. Dose-related reductions in cerebral blood flow $(\mathrm{CBF}), \mathrm{ICP}$, and cerebral metabolic rate have been reported during propofol anesthesia $(4,5)$, while all volatile anesthetics (such as desflurane and sevoflurane, among others) have a direct, dose-dependent vasodilator effect on the cerebral vessels, resulting in an increase in cerebral blood volume and ICP $(4,5)$. It is unclear whether different anesthetics have different influences on ICP due to postural position and $\mathrm{CO}_{2}$ pneumoperitoneum during surgery.

Several studies have shown that the measurement of optic nerve sheath diameter (ONSD) by ultrasound is a noninvasive and repeatable technique for the evaluation of ICP elevation (6,7). Hence, ONSD can be used as a surrogate for the direct measurement of ICP (8) in real time which is simple, accurate, and rapid (9).

To better understand the effects of propofol and inhalational anesthetics on ICP and to provide clinicians with more distinct guidance, we conducted this systematic review to explore the relationship between anesthetic agents and the ONSD. We present the following article in accordance with the PRISMA reporting checklist (10) (available at https://dx.doi.org/10.21037/apm-21-2363).

\section{Methods}

This review was registered in PROSPERO (CRD42021264559).

\section{Search strategy}

Two researchers (YJK and YXP) performed a systematic search in the electronic databases of PubMed, the Cochrane Library, EMBASE, Ovid MEDLINE, and other databases updated to June 2021. The search keywords were "propofol", "sevoflurane", "desflurane", "inhalational anesthetics", "optic nerve sheath diameter", "trendelenburg position", and " $\mathrm{CO}_{2}$ pneumoperitoneum". The search terms of each database were modified. When there was any conflict between the search results of the 2 researchers (YJK and YXP), it was resolved through discussion and an agreement was reached. Appropriate combinations of keywords related to anesthetic agents and ONSD were selected. The following is an example of a search strategy applied to PubMed:

(((()((()((()((()propofol) OR (propofol[MeSH Terms])) AND (sevoflurane)) OR (sevoflurane[MeSH Terms])) OR (desflurane)) OR (desflurane[MeSH Terms])) OR (inhalational anesthetics)) OR (inhalation anesthetics)) OR (inhalation anesthetics[MeSH Terms])) AND (optic nerve sheath diameter)) OR (trendelenburg)) OR (trendelenburg position)) OR (Head-Down Tilt[MeSH Terms])) OR (Trendelenburg Position[MeSH Terms])) OR (Pneumoperitoneum)) OR (Pneumoperitoneum[MeSH Terms])) OR (Artificial Pneumoperitoneum)) OR (Artificial Pneumoperitoneum[MeSH Terms]).

\section{Eligibility criteria}

Before the systematic review and meta-analysis, all authors had predetermined the inclusion criteria. The inclusion criteria were as follows: (I) the study was a randomized controlled trial (RCT), regardless of the states and language; (II) included patients undergoing surgery in the Trendelenburg position with $\mathrm{CO}_{2}$ pneumoperitoneum under general anesthesia; (III) the effect of propofol on the ONSD was compared to the effect of inhalational anesthetics on ONSD in the study; (IV) ONSD measured by ultrasound at various time points was depicted in the trial. The exclusion criteria were as follows: (I) non-RCTs; (II) ongoing studies; (III) the full texts of studies were not available; (IV) unable to extract the outcome data for analysis.

\section{Data collection and quality assessment}

Data extraction was independently performed by 2 researchers (YJK and YXP) according to a standardized Population Intervention Comparison Outcome (PICO) scheme. The extracted information consisted of the year of publication, the first author, study design, type of surgery, intervention, sample size, measure time, and outcome variables. The Cochrane Bias Risk Scale, which covers 7 specific items, was used to assess the methodological quality of these studies (11). The risk of bias for each item 


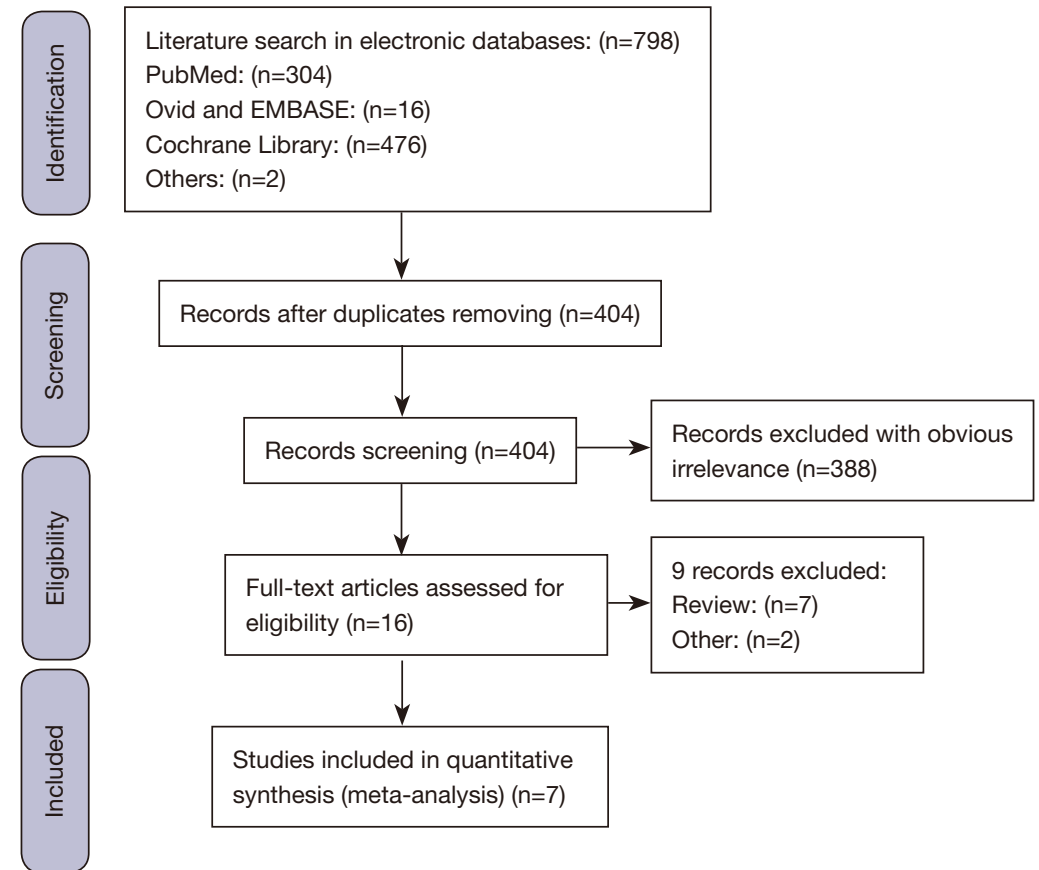

Figure 1 PRISMA flowchart of the included studies. PRISMA, preferred reporting items for systematic reviews and meta-analyses.

was classified as unclear, low, or high. The methodological quality assessments were conducted independently by 2 researchers, and if there was any conflict, it would be properly resolved by a third researcher (LXJ) based on the original report.

\section{Statistical analysis}

Stata (version 16, Stata Corporation) software was used for statistical analysis. The bilateral test level of significance for the pooled data was set at $\alpha=0.05$. The weighted mean difference (WMD) was used as the analysis statistic for continuous variables, and its $95 \%$ confidence interval (CI) was provided. For heterogeneity analyses, data that were significantly homogeneous $\left(\mathrm{P}>0.05\right.$ and $\left.\mathrm{I}^{2}<50.0 \%\right)$ were carefully analyzed with a fixed-effect model. If there was heterogeneity among the study results, the random-effects model was adopted after excluding significant clinical heterogeneity. Sensitivity analysis evaluated the impact of an individual study with a high risk of bias on the stability of the pooled data by excluding one trial at a time (12). Egger's test was performed to assess publication bias, and $\mathrm{P}<0.05$ was regarded as existing publication bias.

\section{Results}

\section{Literature search}

The initial search in PubMed, EMBASE, Ovid MEDLINE, the Cochrane Library, and other databases updated to June 2021 identified 798 reports. Duplication removal reduced the number of reports to 404 . After reviewing titles and abstracts, 388 studies were further excluded. After reading the full texts of the remaining 16 reports, 9 of them were excluded for one or more of the following reasons: the article was a review $(n=7)$, or the research data could not be extracted or used for analysis $(n=2)$. The list of included studies was then reviewed and no new eligible studies were found. Finally, a total of 7 RCTs were included in the metaanalysis (13-19). The flow diagram in Figure 1 illustrates the literature search and trials screening process.

\section{Characteristics of the included studies}

As shown in Table 1, a total number of 798 patients involved in the seven RCTs were enrolled in this metaanalysis (13-19). Among these seven RCTs, six studies used sevoflurane as the inhalational anesthetic for anesthesia 
Table 1 Characteristics of the included studies

\begin{tabular}{|c|c|c|c|c|c|c|c|}
\hline References & Design & The type of surgery & The characteristics of surgery & \multicolumn{2}{|c|}{ Intervention } & Measure time & Outcome \\
\hline $\begin{array}{l}\text { Geng et al., } \\
2021\end{array}$ & $\mathrm{RCT}$ & $\begin{array}{l}\text { Laparoscopic } \\
\text { gynecological surgery }\end{array}$ & $\begin{array}{l}\text { Steep Trendelenburg position, } \\
\mathrm{CO}_{2} \text { pneumoperitoneum }\end{array}$ & $\begin{array}{l}\text { Propofol } \\
\mathrm{N}=58\end{array}$ & $\begin{array}{l}\text { Sevoflurane } \\
\qquad N=58\end{array}$ & [1] [2] [3] & (a) (b) \\
\hline $\begin{array}{l}\text { Yang et al., } \\
2020\end{array}$ & $\mathrm{RCT}$ & $\begin{array}{l}\text { Laparoscopic } \\
\text { gynecological surgery }\end{array}$ & $\begin{array}{l}\text { Steep Trendelenburg position, } \\
\mathrm{CO}_{2} \text { pneumoperitoneum }\end{array}$ & $\begin{array}{l}\text { Propofol } \\
\mathrm{N}=20\end{array}$ & $\begin{array}{l}\text { Sevoflurane } \\
\qquad N=20\end{array}$ & [1] [2] [3] & (a) (b) (c) \\
\hline $\begin{array}{l}\text { Lee et al., } \\
2019\end{array}$ & $\mathrm{RCT}$ & $\begin{array}{l}\text { Robotic or laparoscopic } \\
\text { gynecological surgery }\end{array}$ & $\begin{array}{l}\text { Steep Trendelenburg position, } \\
\mathrm{CO}_{2} \text { pneumoperitoneum }\end{array}$ & $\begin{array}{l}\text { Propofol } \\
\mathrm{N}=25\end{array}$ & $\begin{array}{l}\text { Sevoflurane } \\
\qquad N=25\end{array}$ & [1] [2] [4] & (a) (b) (c) \\
\hline $\begin{array}{l}\text { Sujata et al., } \\
2019\end{array}$ & $\mathrm{RCT}$ & $\begin{array}{l}\text { Robot-assisted pelvic } \\
\text { surgery }\end{array}$ & $\begin{array}{l}\text { Steep Trendelenburg position, } \\
\mathrm{CO}_{2} \text { pneumoperitoneum }\end{array}$ & $\begin{array}{l}\text { Propofol } \\
\mathrm{N}=25\end{array}$ & $\begin{array}{l}\text { Sevoflurane } \\
\qquad N=24\end{array}$ & [2] [3] [4] & (a) \\
\hline $\begin{array}{l}\text { Choi et al., } \\
2018\end{array}$ & $\mathrm{RCT}$ & RALP & $\begin{array}{l}\text { Steep Trendelenburg position, } \\
\mathrm{CO}_{2} \text { pneumoperitoneum }\end{array}$ & $\begin{array}{l}\text { Propofol } \\
\mathrm{N}=28\end{array}$ & $\begin{array}{l}\text { Desflurane } \\
\qquad \mathrm{N}=28\end{array}$ & [1] [3] [4] & (a) (b) (c) \\
\hline
\end{tabular}

(a) = ONSD; (b) = MAP; (c) = PETCO2. [1] T1: 0-10 min after changing to the steep Trendelenburg position and introducing a pneumoperitoneum; [2] T2: 30 min after changing to the steep Trendelenburg position and introducing a pneumoperitoneum; [3] T3: 60 min after changing to the steep Trendelenburg position and introducing a pneumoperitoneum; [4] T4: 0-10 min after returning the patient's position to supine. RCT, randomized controlled trial; RLRP, robot-assisted laparoscopic radical prostatectomy; RALP, robotassisted laparoscopic prostatectomy; ONSD, optic nerve sheath diameter; MAP, mean arterial pressure; $\mathrm{ETCO}_{2}$, end-tidal carbon dioxide.

maintenance (13-18) and 1 study used desflurane as the inhalational anesthetic (19). Three out of the 7 trials included patients who underwent laparoscopic gynecological surgery $(13,14,16)$ or robotic or laparoscopic gynecological surgery, three studies included patients who underwent robot-assisted laparoscopic prostatectomy (RALP) or RLRP surgery $(15,18,19)$, and 1 study (robotassisted pelvic surgery) was not clear (17). The risk of bias in the studies was assessed as described in Figure 2. One study had a high level of risk due to a lack of methods for allocation concealment (14). Three studies (15-17) had an unclear risk of bias because of the unclear random sequence generation or allocation concealment (selection bias), or unclear participant and researcher blindness (performance bias). The remaining three studies all had a low risk of bias.

The assessment of the risk of bias in the included studies. (I) Summary of the risk of bias illustrating the authors' judgments on each item of bias risk for each involved study; (II) graph of the risk of bias illustrating the assessment of bias risk for all included studies expressed as a percentage.

\section{Effects of propofol and inhalational anesthetics on the ONSD}

After collecting and analyzing the data of the 7 studies using propofol or inhalational anesthetics in the maintenance of anesthesia $(n=379$, propofol $=190$, inhalational anesthetics $=189$ ), a random-effects model was used for meta-analysis, and the results suggested that there were borderline significant differences in the ONSD at T2 between propofol and the control group: T2 (WMD $=-0.15,95 \% \mathrm{CI}:-0.31$, $-0.00, \mathrm{P}=0.005)$. There were significant differences at $\mathrm{T} 3$ $(\mathrm{WMD}=-0.23,95 \% \mathrm{CI}:-0.42,-0.05, \mathrm{P}=0.013)$ and $\mathrm{T} 4$ (WMD $=-0.18,95 \%$ CI: $-0.29,-0.07, \mathrm{P}=0.001$ ) (Figure 3). At T1, no significant differences in the ONSD were identified between the two groups after statistical correction: $\mathrm{T} 1$ (WMD =-0.08, 95\% CI: -0.26, 0.10, P=0.368) (Figure 3). Egger's test demonstrated that there was no publication bias in the included studies (Table 2).

\section{Sensitivity analysis}

We conducted sensitivity analyses to evaluate the influence 

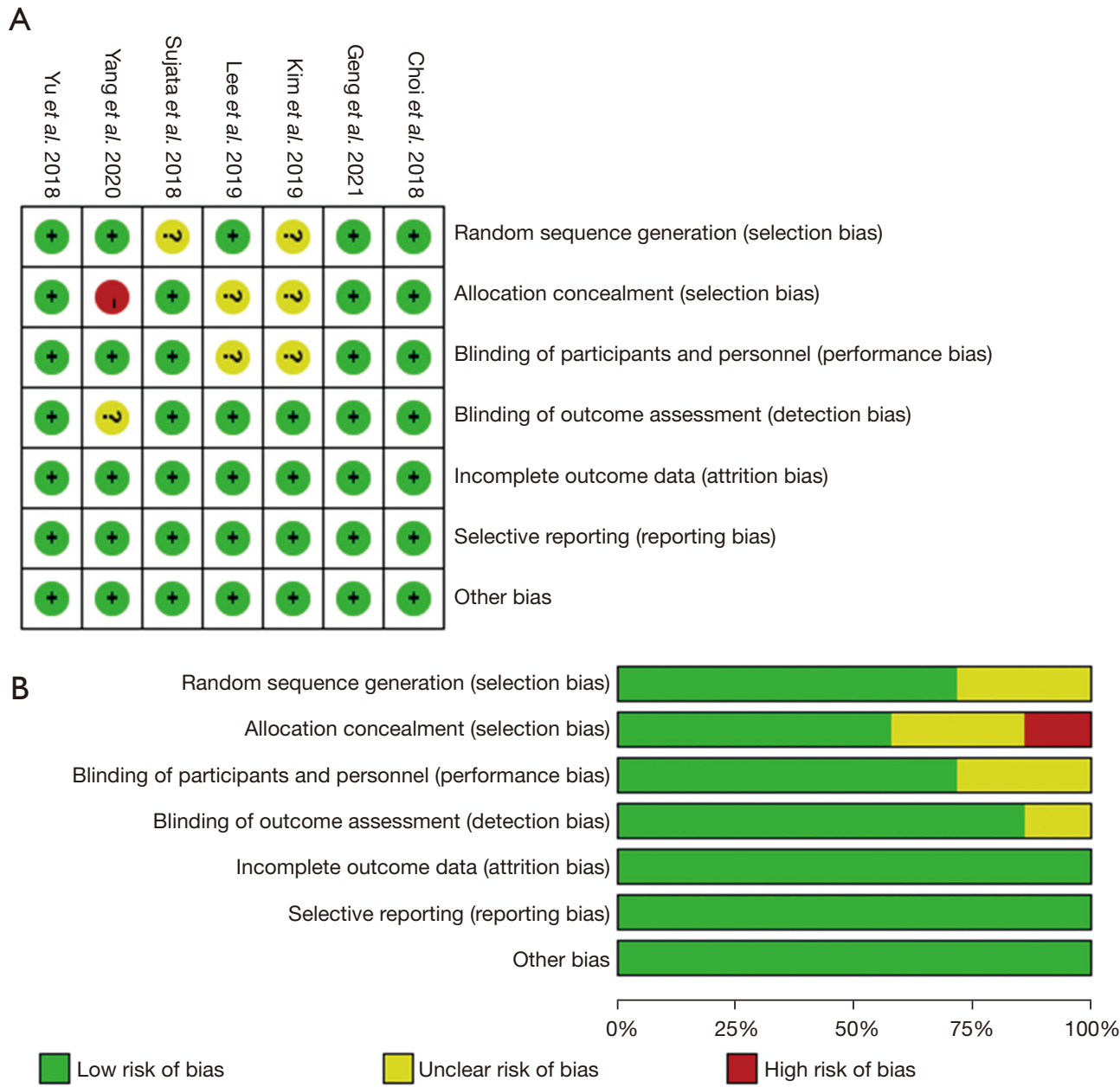

Figure 2 The risk of bias of all the included trials. (A) Risk of bias summary: review authors' judgements about each risk of bias item for each included study. (B) Risk of bias graph: review authors' judgements about each risk of bias item presented as percentages across all included studies.

of each study on the overall effect estimated by omitting one study at a time from the analysis. The sensitivity analysis to estimate the effects of propofol and inhalational anaesthetics on the ONSD is shown in Figure 4A,4B. The results of the sensitivity analysis on the ONSD indicated that no significant effect was observed after excluding any single study and calculating the aggregate outcomes, suggesting that the results were relatively robust.

\section{Comparison of mean arterial pressure (MAP) and end tidal $\mathrm{CO}_{2}\left(\mathrm{ETCO}_{2}\right)$ between the two groups}

The comparison of the MAP and $\mathrm{ETCO}_{2}$ at each point in time between the two groups is illustrated in Figures 5 and 6. There were no significant differences in MAP $(\mathrm{P}=0.654$,
$0.445,0.698$, and 0.562 , respectively $)$ and $\mathrm{ETCO}_{2}(\mathrm{P}=0.081$, $0.506,0.126$, and 0.983 , respectively) at $\mathrm{T} 1, \mathrm{~T} 2, \mathrm{~T} 3$ and $\mathrm{T} 4$ between propofol and inhalational anesthetics.

\section{Discussion}

In the current systematic review and meta-analysis of data from 379 patients in 7 RCTs, we found that the ONSD was significantly lower during propofol anesthesia than during inhalation anesthesia at 30 and 60 minutes after changing to the Trendelenburg position and introducing a pneumoperitoneum.

In comparison of conventional measured method for ICP, such as invasive intracranial monitoring which is associated with risk of complications-in particular 


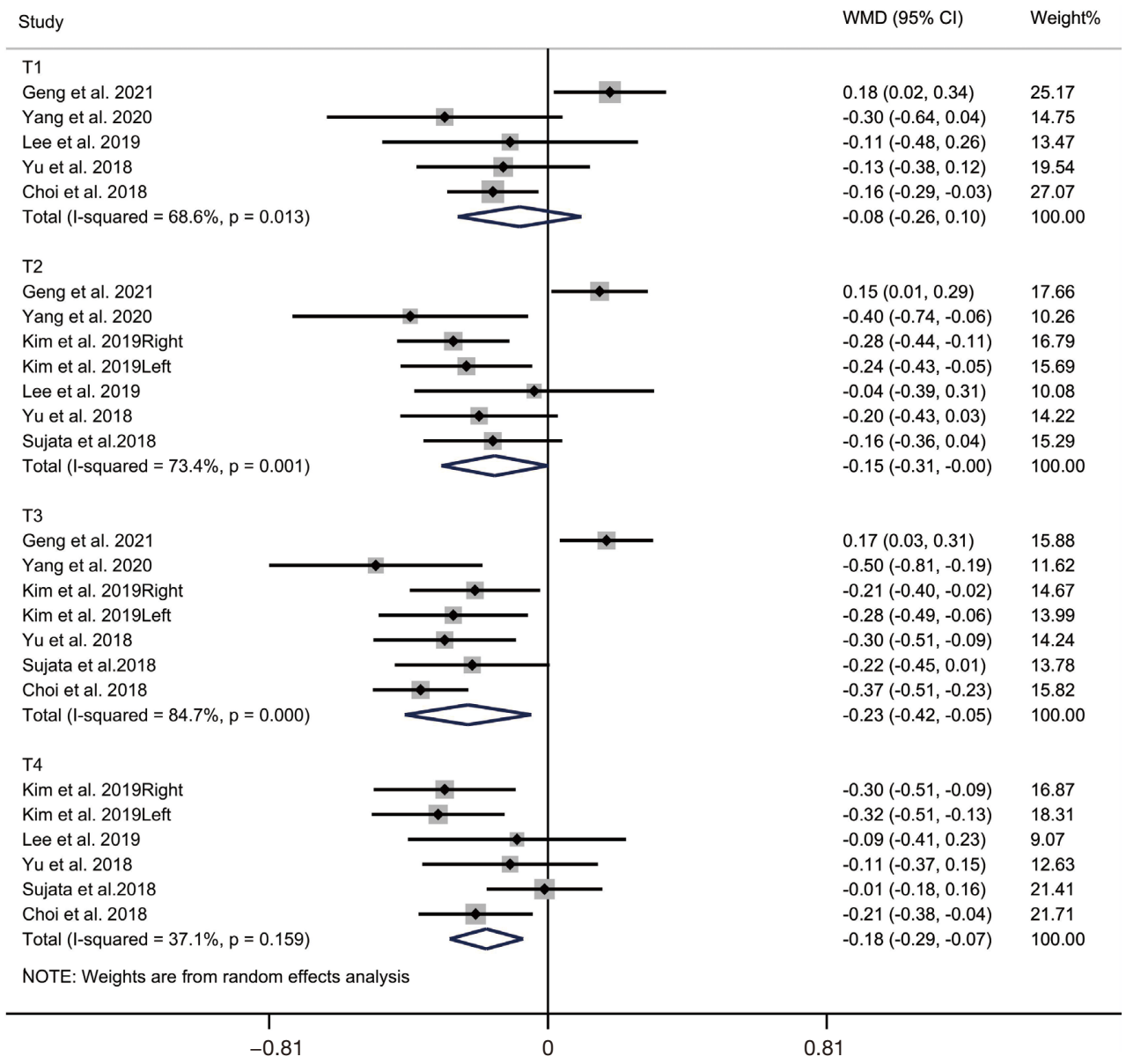

Figure 3 Forest plot for effects of propofol and inhalational anaesthetic on ONSD. ONSD, optic nerve sheath diameter.

Table 2 Egger's test

\begin{tabular}{ccccc}
\hline & T1 & T2 & T3 & T4 \\
\hline Egger's test (WMD) & 0.701 & 0.293 & 0.261 & 0.962 \\
\hline
\end{tabular}

hemorrhage or infection, the measurement of ONSD has the advantages of being low cost, with short investigation times, good reproducibility, and bedside availability, and most importantly of being non-invasive and simple $(6,20)$.

Chin et al. (8) confirmed the relationship between the $\mathrm{ONSD}$ and $\mathrm{CO}_{2}$ pneumoperitoneum in the Trendelenburg position and found that $\mathrm{CO}_{2}$ intraperitoneal infusion increased CBF and eventually led to the increase of ICP, and the Trendelenburg position resulted in a higher intrathoracic pressure leading to increased ICP. Kim et al. claimed that the ONSD increased immediately after establishing a $\mathrm{CO}_{2}$ pneumoperitoneum and adjusting to the steep Trendelenburg position, but then remained unchanged (21).

Sevoflurane has a dose-dependent effect on the relaxation of vascular smooth muscles and vasodilation of intrinsic cerebral vascular, so the CBF increases significantly during sevoflurane anesthesia, leading to increased ICP (22). In addition, it is well known that desflurane causes greater increases in $\mathrm{CBF}$ than sevoflurane. However, doserelated decreases in brain metabolic rate, ICP, and CBF have been reported during propofol anesthesia $(23,24)$. In our review, some studies $(14,15,17-19)$ suggested that propofol anesthesia might help to minimize ICP changes after changing to the Trendelenburg position and introducing a pneumoperitoneum, while others $(13,16)$ suggested that the ONSD was slightly larger with propofol anesthesia compared to inhalational anesthesia, or there was no difference in the ONSD between the two general anesthesia maintenance methods. The depth of anesthesia 

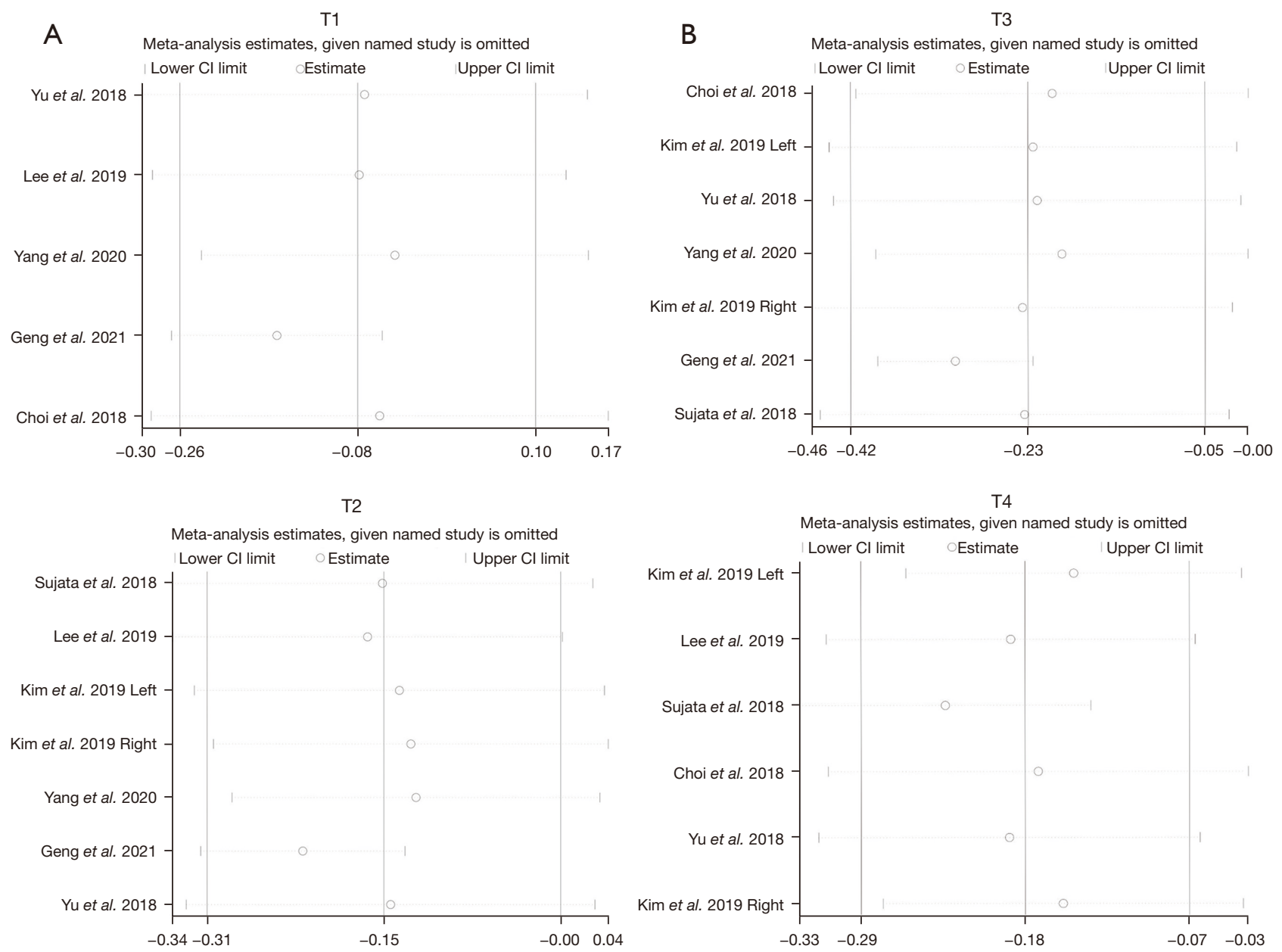

Figure 4 Sensitivity analysis of ONSD. (A) Sensitivity analysis of ONSD on T1 and T2. (B) Sensitivity analysis of ONSD on T3 and T4. ONSD, optic nerve sheath diameter.

and the average age of patients may be the cause of the inconsistent results $(13,16)$. According to a previous study, the changes in the ONSD were related to age during RALP. The ONSD variation was greater in older patients than in patients aged less than 63 years (25), which may suggest that self-regulation of ICP is better in younger patients. The depth of anesthesia may affect the changes in CBF, and thus the changes in ICP and ONSD. However, a study by Lee et al. (16) only maintained the bispectral index (BIS) in the range of 40-60 during the whole procedure, but did not statistically compare the BIS values between the 2 groups. In our review, sensitivity analysis was conducted by excluding studies one by one, but there was no difference in the analysis outcome.

Whiteley et al. reported that the ONSD was positively correlated with MAP (26). Meanwhile, increases in the partial pressure of arterial carbon dioxide $\left(\mathrm{PaCO}_{2}\right)$, which has a strong relationship with $\mathrm{ETCO}_{2}$, lead to robust and rapid increases in CBF (27). However, no significant differences in MAP and $\mathrm{ETCO}_{2}$ were observed between the 2 groups, which might have resulted from vasoactive agents and adjusted ventilator settings in both groups.

\section{Limitations}

Several limitations of this systematic review and metaanalysis should be acknowledged: (I) the quantity of studies and the general combined sample size were relatively small, and the administration of anesthesia varied substantially; (II) the analysis of this study was based on study-level data, without original data from individual patients (contacting the author of the study to obtain the original data was 


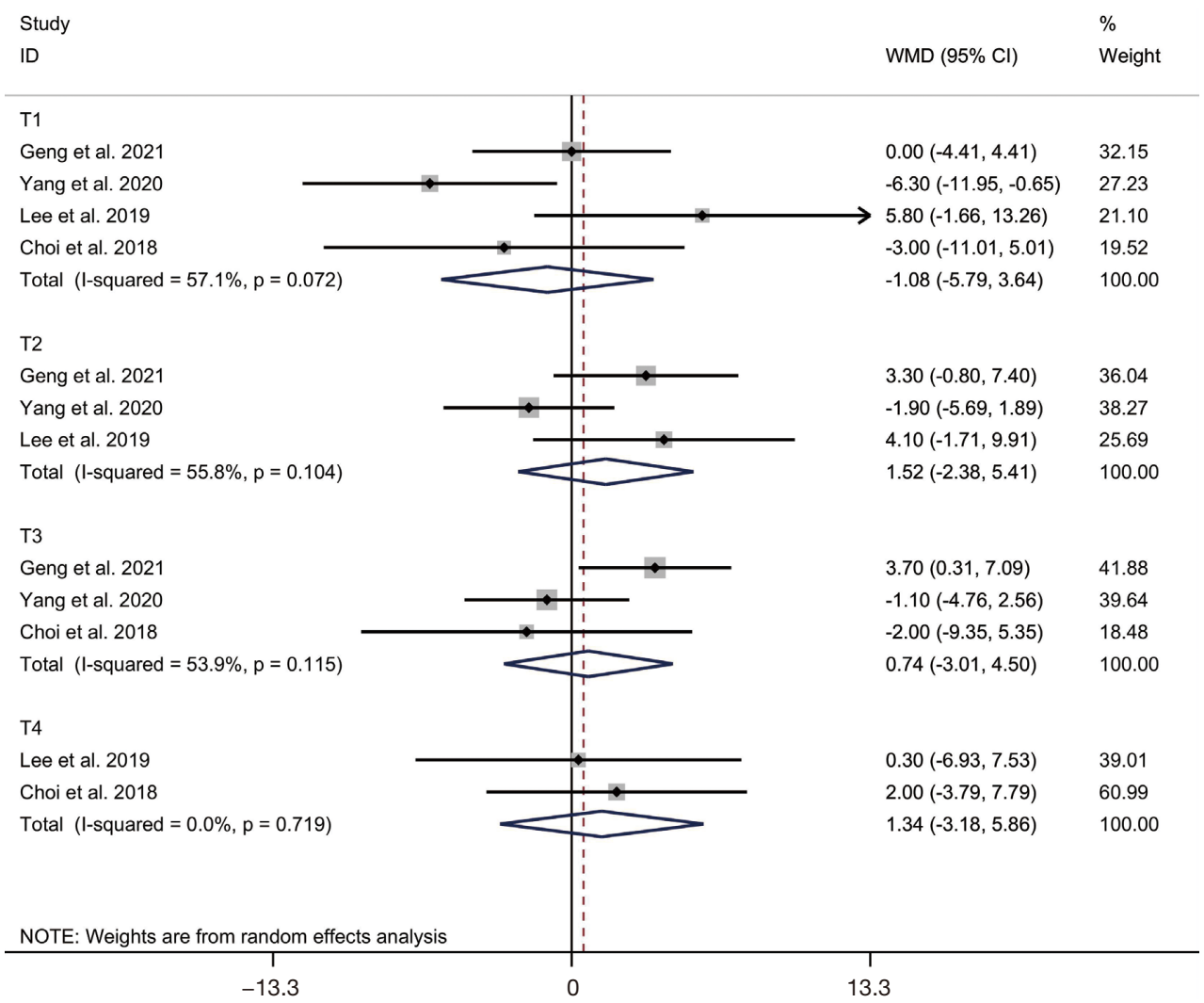

Figure 5 Forest plot for effects of propofol and inhalational anaesthetic on MAP. MAP, mean arterial pressure.

unsuccessful); (III) heterogeneity existed in the metaanalysis. An attempt to eliminate heterogeneity was made using sensitivity analysis, however, heterogeneity still existed due to the various surgery types, patients' ages, and the administration of anesthesia in the included studies, which is unlikely to be eliminated. As such, the current data should be carefully interpreted, and further studies are required to validate the findings.

\section{Conclusions}

In conclusion, the findings of our study indicated that the ONSD was significantly lower during propofol anesthesia than during inhalational anesthesia after adopting the Trendelenburg position and $\mathrm{CO}_{2}$ pneumoperitoneum, suggesting that propofol anesthesia may help to minimize ICP changes compared with inhalational anesthetics. 


\begin{tabular}{|c|c|c|}
\hline \multirow{2}{*}{$\begin{array}{l}\text { Study } \\
\text { ID }\end{array}$} & \multirow[b]{2}{*}{ WMD $(95 \% \mathrm{Cl})$} & \multirow{2}{*}{$\%$} \\
\hline & & \\
\hline \multicolumn{3}{|l|}{ T1 } \\
\hline Yang et al. 2020 & $-1.50(-2.90,-0.10)$ & 35.93 \\
\hline Lee et al. 2019 & $-0.60(-2.01,0.81)$ & 35.38 \\
\hline Choi et al. 2018 & $0.00(-1.57,1.57)$ & 28.69 \\
\hline Total $($ I-squared $=0.8 \%, p=0.365)$ & $-0.75(-1.60,0.09)$ & 100.00 \\
\hline \multicolumn{3}{|l|}{ T2 } \\
\hline Yang et al. 2020 & $-1.20(-2.23,-0.17)$ & 39.59 \\
\hline Kim et al. 2019 & $0.25(-1.23,1.73)$ & 27.33 \\
\hline Lee et al. 2019 & $0.20(-1.05,1.45)$ & 33.08 \\
\hline Total $(\mathrm{I}$-squared $=49.3 \%, \mathrm{p}=0.139$ ) & $-0.34(-1.35,0.66)$ & 100.00 \\
\hline \multicolumn{3}{|l|}{ T3 } \\
\hline Yang et al. 2020 & $-0.90(-1.91,0.11)$ & 58.43 \\
\hline Kim et al. 2019 & $-0.38(-2.11,1.35)$ & 19.89 \\
\hline Choi et al. 2018 & $0.00(-1.66,1.66)$ & 21.68 \\
\hline Total $($ I-squared $=0.0 \%, p=0.636)$ & $-0.60(-1.37,0.17)$ & 28.76 \\
\hline \multicolumn{3}{|l|}{ T4 } \\
\hline Kim et al. 2019 & $-0.62(-2.81,1.57)$ & 36.87 \\
\hline Lee et al. 2019 & $-0.70(-2.24,0.84)$ & 48.71 \\
\hline Choi et al. 2018 & $4.00(-0.48,8.48)$ & 14.72 \\
\hline Total $(I-$ squared $=48.5 \%, p=0.143)$ & $0.02(-1.91,1.95)$ & 100.00 \\
\hline \multicolumn{3}{|l|}{ NOTE: Weights are from random effects analysis } \\
\hline $\begin{array}{c}1 \\
-8.48\end{array}$ & & \\
\hline
\end{tabular}

Figure 6 Forest plot for effects of propofol and inhalational anaesthetic on $\mathrm{ECTCO}_{2}$.

\section{Acknowledgments}

Funding: None.

\section{Footnote}

Reporting Checklist: The authors have completed the PRISMA reporting checklist. Available at https://dx.doi. org/10.21037/apm-21-2363

Conflicts of Interest: All authors have completed the ICMJE uniform disclosure form (available at https://dx.doi. org/10.21037/apm-21-2363). The authors have no conflicts of interest to declare.

Ethical Statement: The authors are accountable for all aspects of the work in ensuring that questions related to the accuracy or integrity of any part of the work are appropriately investigated and resolved.

Open Access Statement: This is an Open Access article distributed in accordance with the Creative Commons Attribution-NonCommercial-NoDerivs 4.0 International License (CC BY-NC-ND 4.0), which permits the noncommercial replication and distribution of the article with the strict proviso that no changes or edits are made and the original work is properly cited (including links to both the formal publication through the relevant DOI and the license). See: https://creativecommons.org/licenses/by-nc-nd/4.0/.

\section{References}

1. Chen K, Wang L, Wang Q, et al. Effects of pneumoperitoneum and steep Trendelenburg position on cerebral hemodynamics during robotic-assisted laparoscopic radical prostatectomy: A randomized controlled study. Medicine (Baltimore) 2019;98:e15794.

2. Gainsburg DM. Anesthetic concerns for robotic-assisted laparoscopic radical prostatectomy. Minerva Anestesiol 2012;78:596-604.

3. Park EY, Koo BN, Min KT, et al. The effect of 
pneumoperitoneum in the steep Trendelenburg position on cerebral oxygenation. Acta Anaesthesiol Scand 2009;53:895-9.

4. Hassan WMNW, Nasir YM, Zaini RHM, et al. Targetcontrolled Infusion Propofol Versus Sevoflurane Anaesthesia for Emergency Traumatic Brain Surgery: Comparison of the Outcomes. Malays J Med Sci 2017;24:73-82.

5. Ravussin P, Strebel S. Propofol for neuroanesthesia. Anaesthesist 1995;44:405-9.

6. Lochner P, Czosnyka M, Naldi A, et al. Optic nerve sheath diameter: present and future perspectives for neurologists and critical care physicians. Neurol Sci 2019;40:2447-57.

7. Hylkema C. Optic Nerve Sheath Diameter Ultrasound and the Diagnosis of Increased Intracranial Pressure. Crit Care Nurs Clin North Am 2016;28:95-9.

8. Chin JH, Seo H, Lee EH, et al. Sonographic optic nerve sheath diameter as a surrogate measure for intracranial pressure in anesthetized patients in the Trendelenburg position. BMC Anesthesiol 2015;15:43.

9. Maissan IM, Dirven PJ, Haitsma IK, et al. Ultrasonographic measured optic nerve sheath diameter as an accurate and quick monitor for changes in intracranial pressure. J Neurosurg 2015;123:743-7.

10. Moher D, Liberati A, Tetzlaff J, et al. Preferred reporting items for systematic reviews and meta-analyses: the PRISMA statement. BMJ 2009;339:b2535.

11. Higgins J, Altman DG. Assessing risk of bias in included studies. In: Higgins J, Green S. editors. Cochrane Handbook for Systematic Reviews of Interventions 5.0.1. Oxford, England: Cochrane Collaboration, 2008.

12. Deeks JJ, Higgins JPT, Altman DG. Analyzing data and undertaking meta-analyses. In: Higgins J, Green S, editors. Cochrane Handbook for Systematic Reviews of Interventions 5.0.1. Oxford, UK: The Cochrane Collaboration, 2008.

13. Geng W, Chen C, Sun X, et al. Effects of sevoflurane and propofol on the optic nerve sheath diameter in patients undergoing laparoscopic gynecological surgery: a randomized controlled clinical studies. BMC Anesthesiol 2021;21:30.

14. Yang G, Zhu Z, Zheng H, et al. Effects of propofol and sevoflurane on optic nerve sheath diameter in patients undergoing gynecological laparoscopic surgery. Journal of Clinical Anesthesiology 2020;36:1059-62.

15. Kim Y, Choi S, Kang S, et al. Propofol Affects Optic Nerve Sheath Diameter less than Sevoflurane during
Robotic Surgery in the Steep Trendelenburg Position. Biomed Res Int 2019;2019:5617815.

16. Lee YY, Lee H, Park HS, et al. Optic nerve sheath diameter changes during gynecologic surgery in the Trendelenburg position: comparison of propofol-based total intravenous anesthesia and sevoflurane anesthesia. Anesth Pain Med (Seoul) 2019;14:393-400.

17. Sujata N, Tobin R, Tamhankar A, et al. A randomised trial to compare the increase in intracranial pressure as correlated with the optic nerve sheath diameter during propofol versus sevoflurane-maintained anesthesia in robot-assisted laparoscopic pelvic surgery. J Robot Surg 2019;13:267-73.

18. Yu J, Hong JH, Park JY, et al. Propofol attenuates the increase of sonographic optic nerve sheath diameter during robot-assisted laparoscopic prostatectomy: a randomized clinical trial. BMC Anesthesiol 2018;18:72.

19. Choi ES, Jeon YT, Sohn HM, et al. Comparison of the effects of desflurane and total intravenous anesthesia on the optic nerve sheath diameter in robot assisted laparoscopic radical prostatectomy: A randomized controlled trial. Medicine (Baltimore) 2018;97:e12772.

20. Robba C, Santori G, Czosnyka M, et al. Optic nerve sheath diameter measured sonographically as non-invasive estimator of intracranial pressure: a systematic review and meta-analysis. Intensive Care Med 2018;44:1284-94.

21. Kim MS, Bai SJ, Lee JR, et al. Increase in intracranial pressure during carbon dioxide pneumoperitoneum with steep trendelenburg positioning proven by ultrasonographic measurement of optic nerve sheath diameter. J Endourol 2014;28:801-6.

22. Chui J, Mariappan R, Mehta J, et al. Comparison of propofol and volatile agents for maintenance of anesthesia during elective craniotomy procedures: systematic review and meta-analysis. Can J Anaesth 2014;61:347-56.

23. Moss E, Price DJ. Effect of propofol on brain retraction pressure and cerebral perfusion pressure. Br J Anaesth 1990;65:823-5.

24. Alkire MT, Haier RJ, Barker SJ, et al. Cerebral metabolism during propofol anesthesia in humans studied with positron emission tomography. Anesthesiology 1995;82:393-403; discussion 27A.

25. Blecha S, Harth M, Schlachetzki F, et al. Changes in intraocular pressure and optic nerve sheath diameter in patients undergoing robotic-assisted laparoscopic prostatectomy in steep $45^{\circ}$ Trendelenburg position. BMC Anesthesiol 2017;17:40.

26. Whiteley JR, Taylor J, Henry M, et al. Detection 
of elevated intracranial pressure in robot-assisted laparoscopic radical prostatectomy using ultrasonography of optic nerve sheath diameter. J Neurosurg Anesthesiol 2015;27:155-9.

27. Hoiland RL, Fisher JA, Ainslie PN. Regulation of the

Cite this article as: Yang J, Yang X, Li X, Ou S. Effects of propofol and inhalational anesthetics on the optic nerve sheath diameter in patients undergoing surgery in the steep Trendelenburg position: a systematic review and meta-analysis. Ann Palliat Med 2021;10(10):10475-10485. doi: 10.21037/apm-212363
Cerebral Circulation by Arterial Carbon Dioxide. Compr Physiol 2019;9:1101-54.

(English Language Editor: C. Betlazar-Maseh) 